Karina Desiree, ${ }^{1}$ Carla L. Schwan, ${ }^{1}$ Visoth Ly, ${ }^{2}$ Lyda Hok, ${ }^{3,4}$ Londa Nwadike, ${ }^{5}$ Randall K. Phebus ${ }^{1}$ and Jessie L. Vipham ${ }^{1 *}$

${ }^{1}$ Dept. of Animal Sciences and Industry, Food Science Institute, Kansas State University, Manhattan, KS 66506, USA

2Faculty of Agro-Industry, Royal University of Agriculture, Phnom Penh, Cambodia ${ }^{3}$ Faculty of Agronomy, Royal University of Agriculture, Phnom Penh, Cambodia ${ }^{4}$ Center of Excellence on Sustainable Agricultural Intensification and Nutrition, Royal University of Agriculture, Phnom Penh, Cambodia ${ }^{5}$ Research and Extension, Kansas State University and the University of Missouri, Kansas City, KS 64110, USA
PEER-REVIEWED ARTICLE

Food Protection Trends, Vol 40, No. 5, p. 349-362 Copyright 2020 , International Association for Food Protection 2900 100th Street, Suite 309, Des Moines, IA 50322-3855
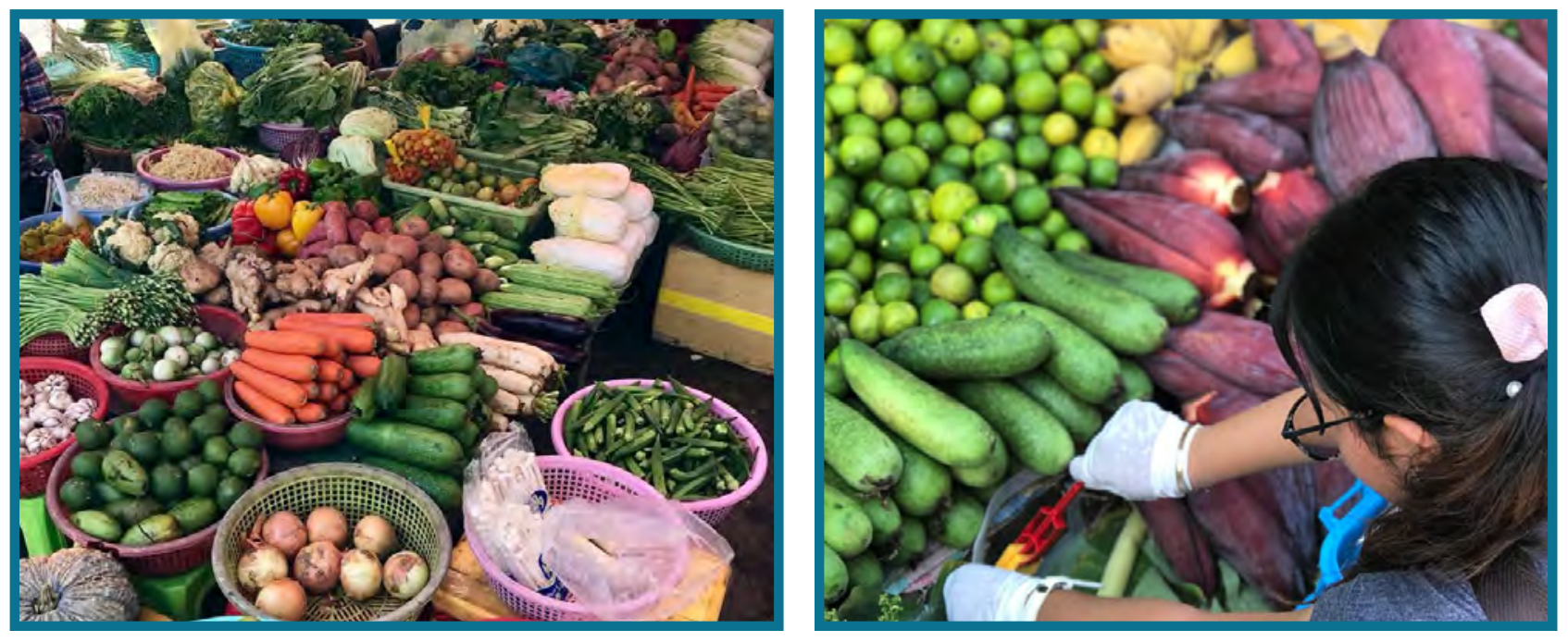

\title{
Defining the Flow and Food Safety Behaviors of Actors in the Cambodian Vegetable Value Chain
}

\section{ABSTRACT}

The vegetable value chain contributes heavily to human livelihoods in Cambodia, from the perspective of human nutrition, income generation, and agricultural prosperity. This paper seeks to define the flow of vegetable crops within the vegetable value chain in Cambodia and provides insight into potential contamination points for bacterial hazards. A total of 102 vegetable farmers, 21 vegetable collectors, 30 vegetable distributors, and 100 vegetable vendors were interviewed about sanitation and hygiene practices. Visual assessments of vegetable handling practices and market conditions, as they pertain to food safety, were also conducted at the market level. Findings showed several deficiencies in food safety practices, including (1) the use of inadequately composted manure and improper harvest intervals after manure application; (2) the common practice of cutting out bruised portions of vegetables; (3) a lack of cool storage; (4) a lack of hygienic practices during transport and marketing, and [5] a lack of adequate infrastructure (tables, roofing, etc.) and hygienic infrastructure (functioning drains, cleanable surfaces, etc.) within markets. These factors increase the likelihood of bacterial contamination of vegetables, posing a threat to public health and weakening consumer confidence in vegetables produced and sold in Cambodia. These findings can support the development of suitable food safety intervention strategies for Cambodia.

\section{INTRODUCTION}

Food safety, as a discipline, is a multi-stakeholder activity. As a food product moves through a specific agriculture value chain (i.e., on farm, processing, storage, transportation and retail), it is critical that all agriculture value chain actors actively contribute to ensuring the safe handling of all food products. Food safety is effectively maintained from "farm to fork" by the implementation of multiple prerequisite programs and/or interventions and practices, such as sanitation programs, good agriculture practices/good manufacturing practices (GAP/GMP), temperature control, sanitizers, and heat treatments $(31,34)$. These types of multi-hurdle approaches, when implemented properly, are more effective than individual 
interventions at reducing and eliminating food safety hazards (23). Consequently, the multi-hurdle approach provides a safer product and a shared contribution by all value-chain actors. However, these types of approaches require proper investments in food safety capacity within a given agriculture value chain. Unfortunately, many lowand middle-income countries (LMIC) lack the necessary investments, infrastructure, and governance to create strong food safety systems at the community level and therefore face large obstacles in terms of the control of foodborne hazards within multiple food value chains.

In the country of Cambodia- a country with a population of nearly 15.3 million-child mortality rates are high, with over 10,000 child deaths per year being attributed to diarrheal diseases $(27,41)$. The majority of these disease cases have not been traced back to a particular source; however, the likelihood is high that contaminated foods contribute heavily to the occurrence of diarrheal diseases in a LMIC (17). The Cambodian diet consists predominantly of uncooked vegetables (lettuce, tomatoes, carrots, cucumbers, Thai eggplants, etc.) that are commonly purchased through informal market systems, which "escape effective health and safety regulation, and are often untaxed and unlicensed" $(35,38)$. In fact, a majority of vegetables in Cambodia are sold through these markets (38). Informal markets commonly source vegetables through the countries' vegetable value chain, which consists of several actors, all of whom have a role to play in food safety. These actors include farmers, collectors, distributors and vendors (38). Farmers grow and harvest vegetables, which are then transported by the collectors to the distributors that sell vegetables in bulk. Collectors also procure vegetables from the neighboring countries of Thailand and Vietnam. Finally, vegetables are transported from the distributors to the markets by the vendors or by other collectors (e.g., hotels or restaurants) before they reach households or mass consumers (Fig. 1).

Contaminated vegetables have a high potential to cause foodborne diseases and have been implicated in multiple outbreaks worldwide $(15,30)$. Without proper handling along the value chain, pathogens can easily be transferred from the natural environment to vegetables, increasing the consumer's likelihood of acquiring a foodborne illness. In Cambodia, commonly recommended hygiene and sanitation practices are frequently neglected. Furthermore, the control of the vegetable value chain in Cambodia is deficient in the areas of policy, regulations, guidelines, and training and education (25). Consequently, stakeholders within the vegetable value chain are unaware of the food safety risks and may not use proper handling practices to minimize cross-contamination. For these reasons, it was thought important to conduct an explorative review of the Cambodian vegetable value chain that defines the flow of products within the value chain and provides insights on potential contamination points. For the purpose of this study, comparisons of practices between actors were not analyzed with a statistical model, as such an analysis was not appropriate for the type of data collected.

The two main objectives of this study were (1) to describe the flow of vegetables and characterize the
A.

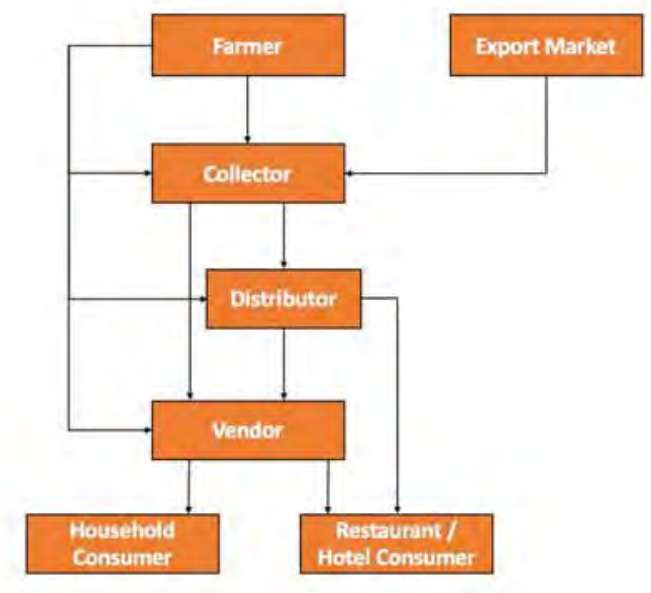

B.

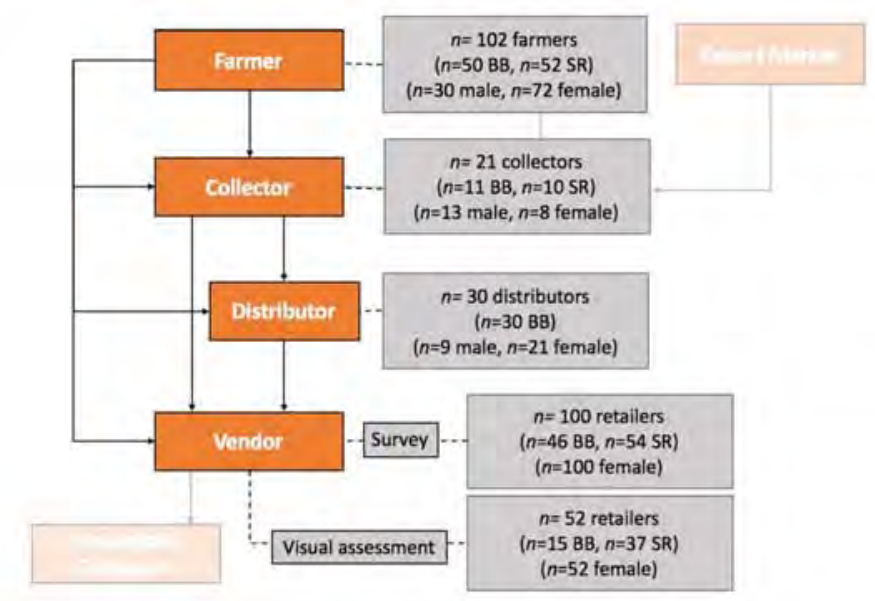

FIGURE 1. A visual schematic of (A) Cambodian vegetable value chain as described by Sokhen et al. (2004) and

(B) Cambodian vegetable value chain explored as a part of the current study design. 
behaviors of value chain actors within the Cambodian vegetable value chain by conducting personal interviews and (2) to identify potential practices that contribute to the cross-contamination of vegetables moving throughout the value chain. Information from this study will be a valuable resource for the creation of strong food safety recommendations and targeted interventions that will prevent the contamination of vegetables in Cambodia.

\section{MATERIALS AND METHODS}

The research protocol and data collection tools were reviewed and approved by the Institutional Review Board at Kansas State University (IRB \#8821.1).

\section{Participants and data collection}

A survey tool with four different questionnaires was designed to investigate food safety practices of Cambodian farmers, collectors, distributors and vendors. Each questionnaire consisted of a different set of questions designed to investigate sanitation and hygiene practices at the various steps of the vegetable value chain and was created with online software developed by Harvard Humanitarian Initiative to serve as a "suite of tools for field data collection" (KoBoToolbox, Harvard Humanitarian Initiative; (22). This software was chosen because of a unique feature that allows surveys to be taken in offline mode, which allowed for data collection and storage in areas without an Internet connection.

Despite the presence of imported vegetables, the survey solely focused on local actors. For this reason, the handling practices related to imported vegetables were not evaluated at the farm level, although they were considered at the collector, distributor, and vendor levels. Additionally, an observational assessment was conducted in informal markets, to examine the food safety practices of vendors, as well as the hygiene condition of bathroom facilities.

Survey questionnaires were developed in English and translated into Khmer (the local language) and orally administered, by students from the Royal University of Agriculture (RUA), Phnom Penh, Cambodia, to participants through an in-person one-on-one interview. The survey was administered orally to gain more reflective answers, ensure the respondents' understanding of complex questions, and maintain quality control over response rate. Students were trained and the questionnaire was field-tested prior to survey administration. Participants were classified as one of the four vegetable value chain actor types initially identified by Sokhen et al. (38): (1) farmers, (2) collectors, (3) distributors, or (4) vendors. Informed consent, as well as participant category, was ensured by verbal confirmation before survey administration. At the end of data collection, a total of 102 farmers, 21 collectors, 30 distributors, and 100 vendors were interviewed. Interviews were conducted in Battambang (rural; 137 respondents) and Siem Reap (peri-urban; 116 respondents) provinces. Differences in interview numbers were based upon the number of market vendors in each location. In addition, visual assessments were conducted on 52 (15 in Battambang province and 37 in Siem Reap province) vegetable vendors.

Battambang province is located in the northwest region of Cambodia (4) and is considered a rural province. In contrast, Siem Reap province, which is also located in the northwest region of the country, is a peri-urban province (i.e., an interface between rural and urban areas, which functions to provide food and natural resources to the cities through agriculture activities (13)). The rationale for selection of these provinces was based upon (1) their classification as United States Agency for International Development (USAID) Feed the Future Zones of Inquiry; (2) differences in socioeconomic status and demographics (28); and (3) the fact that a parallel study of the microbial contamination of vegetables was also being conducted in these two provinces.

\section{Farmer questionnaire}

The farmer questionnaire examined the food safety practices of farmers, with a focus on the cultivation and harvesting of vegetable crops. Topics included the type of vegetables grown, type of soil amendments used, cleaning and storage practices for harvested vegetables, etc. (select questions are outlined in Table 1). Conditional questions were included to capture data on organic fertilizer use, such as aging time (for compost) and time interval between application and harvest (for fresh manure).

\section{Collector questionnaire}

As collectors are generally the value chain actors most heavily involved with the transportation of crops, the collector questionnaire focused on the food safety practices during the transport of vegetables. Questions were asked about topics that included the following: the person and location the vegetables were purchased from; the cleaning, inspecting and sorting process of vegetables received; the type and cleaning practices used for transport vehicles, and the storage method for received vegetables.

\section{Distributor and vendor questionnaire}

Both the distributor and vendor survey questionnaires focused on the handling of vegetables during selling. Topics covered in questions included the person and location the vegetables were purchased from, the cleaning, inspecting and sorting process of received vegetables, the basic food safety and hygiene practices during preparation of selling areas, etc. Visual assessments for vendors consisted of observations on basic food safety practices (e.g., handwashing, tarp condition) and stall sanitation (e.g., vendor location within the market). Visual assessment of bathrooms consisted of observations of facility condition and availability of handwashing stations. 


\section{TABLE 1. Selected survey responses of value-chain actors (overall]}

\begin{tabular}{|c|c|c|}
\hline & Responses & $\begin{array}{l}\text { Percentage of } \\
\text { respondents } \\
(\%)\end{array}$ \\
\hline \multirow{9}{*}{$\begin{array}{l}\text { Farmers } \\
(n=102)\end{array}$} & \multicolumn{2}{|l|}{ I use the following type of fertilizer for my crops: } \\
\hline & (a) Inorganic fertilizer & $56 \%$ \\
\hline & (b) Fresh manure & $33 \%$ \\
\hline & (c) "Composted" animal waste & $11 \%$ \\
\hline & \multicolumn{2}{|l|}{ I do not clean harvested vegetables because: } \\
\hline & (a) a visually clean vegetable does not need to be washed & $55 \%$ \\
\hline & (b) the vegetables will be sold to a different value chain actor who will clean the vegetables & $19 \%$ \\
\hline & (c) I am afraid of spoilage from washing & $13 \%$ \\
\hline & (d) customers asked me to not wash the vegetables & $3 \%$ \\
\hline \multirow{15}{*}{$\begin{array}{l}\text { Collectors } \\
(n=21)\end{array}$} & \multicolumn{2}{|l|}{ I do not clean received vegetables because: } \\
\hline & $\begin{array}{l}\text { (a) I believe that the vegetables had been washed by previous actors } \\
\text { (e.g., local farmers, export distributor) }\end{array}$ & $47 \%$ \\
\hline & (b) a visually clean vegetable does not need to be washed & $33 \%$ \\
\hline & (c) I am afraid of spoilage from washing & $20 \%$ \\
\hline & \multicolumn{2}{|l|}{ If I see bruises and cuts on my received vegetables, I will: } \\
\hline & (a) discard the vegetables & $55 \%$ \\
\hline & (b) return the vegetables & $25 \%$ \\
\hline & (c) sell the vegetables as they are & $10 \%$ \\
\hline & (d) cut out the bruised part and sell the vegetables & $10 \%$ \\
\hline & \multicolumn{2}{|l|}{ My mode of transportation for delivering vegetables is: } \\
\hline & (a) Car & $36 \%$ \\
\hline & (b) Motorcycle & $20 \%$ \\
\hline & (c) Cart attached to a motorcycle & $20 \%$ \\
\hline & (d) Truck with open cargo & $16 \%$ \\
\hline & (e) Truck or car with refrigeration unit & $8 \%$ \\
\hline \multirow{12}{*}{$\begin{array}{l}\text { Distributors } \\
(n=30)\end{array}$} & \multicolumn{2}{|l|}{ I do not clean received vegetables because: } \\
\hline & (a) a visually clean vegetable does not need to be washed & $92 \%$ \\
\hline & $\begin{array}{l}\text { (b) I believe that the vegetables had been washed by previous actors } \\
\text { (e.g., local farmers, export distributor) }\end{array}$ & $8 \%$ \\
\hline & \multicolumn{2}{|l|}{ If I see bruises and cuts on my received vegetables, I will: } \\
\hline & (a) cut the bruised part and sell the vegetables & $60 \%$ \\
\hline & (b) discard the vegetables & $30 \%$ \\
\hline & (c) return the vegetables & $10 \%$ \\
\hline & \multicolumn{2}{|l|}{ Vegetables are transported to the distribution center using: } \\
\hline & (a) Car & $68 \%$ \\
\hline & (b) Truck with open cargo & $23 \%$ \\
\hline & (c) Motorcycle & $6 \%$ \\
\hline & (d) Cart attached to a motorcycle & $3 \%$ \\
\hline
\end{tabular}




\section{TABLE 1. Selected survey responses of value-chain actors overall (cont.)}

\begin{tabular}{|c|c|c|}
\hline & Responses & $\begin{array}{c}\text { Percentage of } \\
\text { respondents } \\
(\%)\end{array}$ \\
\hline \multirow{5}{*}{$\begin{array}{l}\text { Distributors } \\
(n=30)\end{array}$} & \multicolumn{2}{|l|}{ I clean my stall area before selling vegetables by: } \\
\hline & (a) sweeping the stall using a broom & $73 \%$ \\
\hline & (b) I don't clean because the stall already looks clean & $15 \%$ \\
\hline & (c) wiping the stall with water & $8 \%$ \\
\hline & (d) wiping the stall with water and soap/disinfectant & $4 \%$ \\
\hline \multirow{19}{*}{$\begin{array}{l}\text { Vendors } \\
(n=100)\end{array}$} & \multicolumn{2}{|l|}{ I do not clean received vegetables because: } \\
\hline & (a) a visually clean vegetable does not need to be washed & $64 \%$ \\
\hline & (b) I believe that the vegetables had been washed by previous actors & $19 \%$ \\
\hline & (c) I am afraid of spoilage from washing & $17 \%$ \\
\hline & \multicolumn{2}{|l|}{ If I see bruises and cuts on my received vegetables, I will: } \\
\hline & (a) discard the vegetables & $52 \%$ \\
\hline & (b) cut out the bruised part and sell the vegetables & $28 \%$ \\
\hline & (c) return the vegetables & $16 \%$ \\
\hline & (d) sell the vegetables as they are & $4 \%$ \\
\hline & \multicolumn{2}{|l|}{ Vegetables are transported to the informal market using: } \\
\hline & (a) Motorcycle & $58 \%$ \\
\hline & (b) Cart attached to a motorcycle & $24 \%$ \\
\hline & (c) Car & $13 \%$ \\
\hline & (d) Truck with open cargo & $5 \%$ \\
\hline & \multicolumn{2}{|l|}{ I clean my stall area before selling vegetables by: } \\
\hline & (a) sweeping the stall using a broom & $44 \%$ \\
\hline & (b) wiping the stall with water & $34 \%$ \\
\hline & (c) I don't clean because the stall already looks clean & $12 \%$ \\
\hline & (d) wiping the stall with water and soap/disinfectant & $10 \%$ \\
\hline
\end{tabular}

Farmers and collectors in the study were randomly selected from multiple villages in Battambang provinces (BB) and Siem Reap provinces (SR). Distributors were selected from a central distribution center for the Northern Region of Cambodia. Vendors were selected from six markets within BB and SR, where microbial analysis samples for a separate study were also collected. Finally, gender and province data were also collected in each questionnaire.

Data were exported from KoboToolBox (22) and analyzed in terms of descriptive statistics. Additionally, data was disaggregated by gender and province to reveal differences in food safety practices based on location and gender of respondents. Because of the nature of the data, a statistical model was not generated for use in making comparisons in this study.

\section{RESULTS}

\section{Farmers}

Farmers who participated in the study $(n=102)$ consisted of 30 males and 72 females; 50 were situated in BB and 52 in SR. Findings suggest that leafy greens and salad vegetables (e.g., lettuce, cucumber and Chinese broccoli; 74\%), podded vegetables (e.g., long beans; $20 \%$ ) and flower buds (e.g., cauliflower; 4\%) are the major vegetable crops cultivated by the farmers in this study (Fig. 2). A majority of the farmers interviewed utilized inorganic fertilizer, followed by fresh manure and "composted" animal waste (Table 1). In this study, fresh manure is defined as animal waste that has not undergone an aging process (i.e., not stored, not exposed to the sun, not turned). "Composted" animal waste was considered 


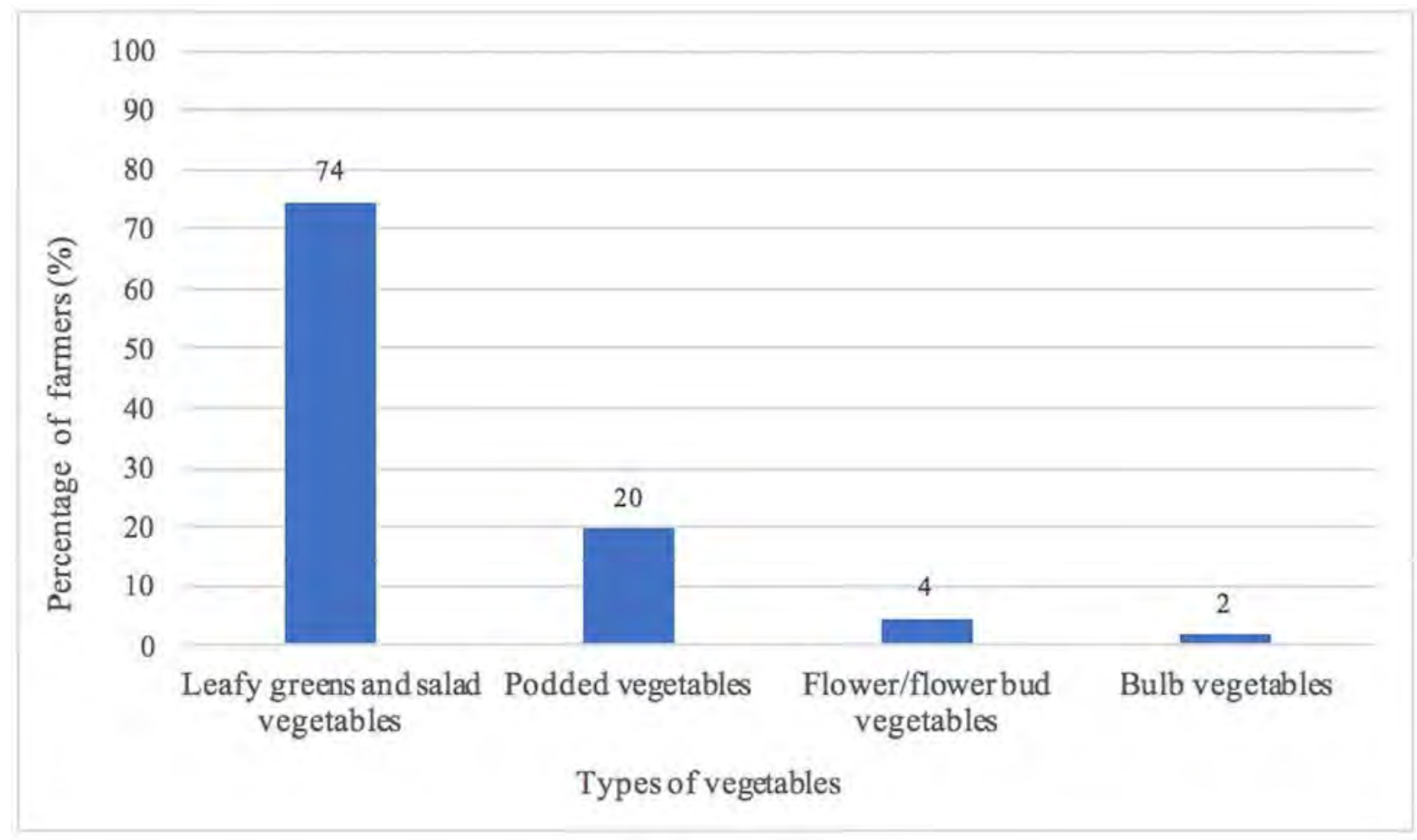

FIGURE 2. Different types of vegetables grown by farmer respondents $(n=102)$.

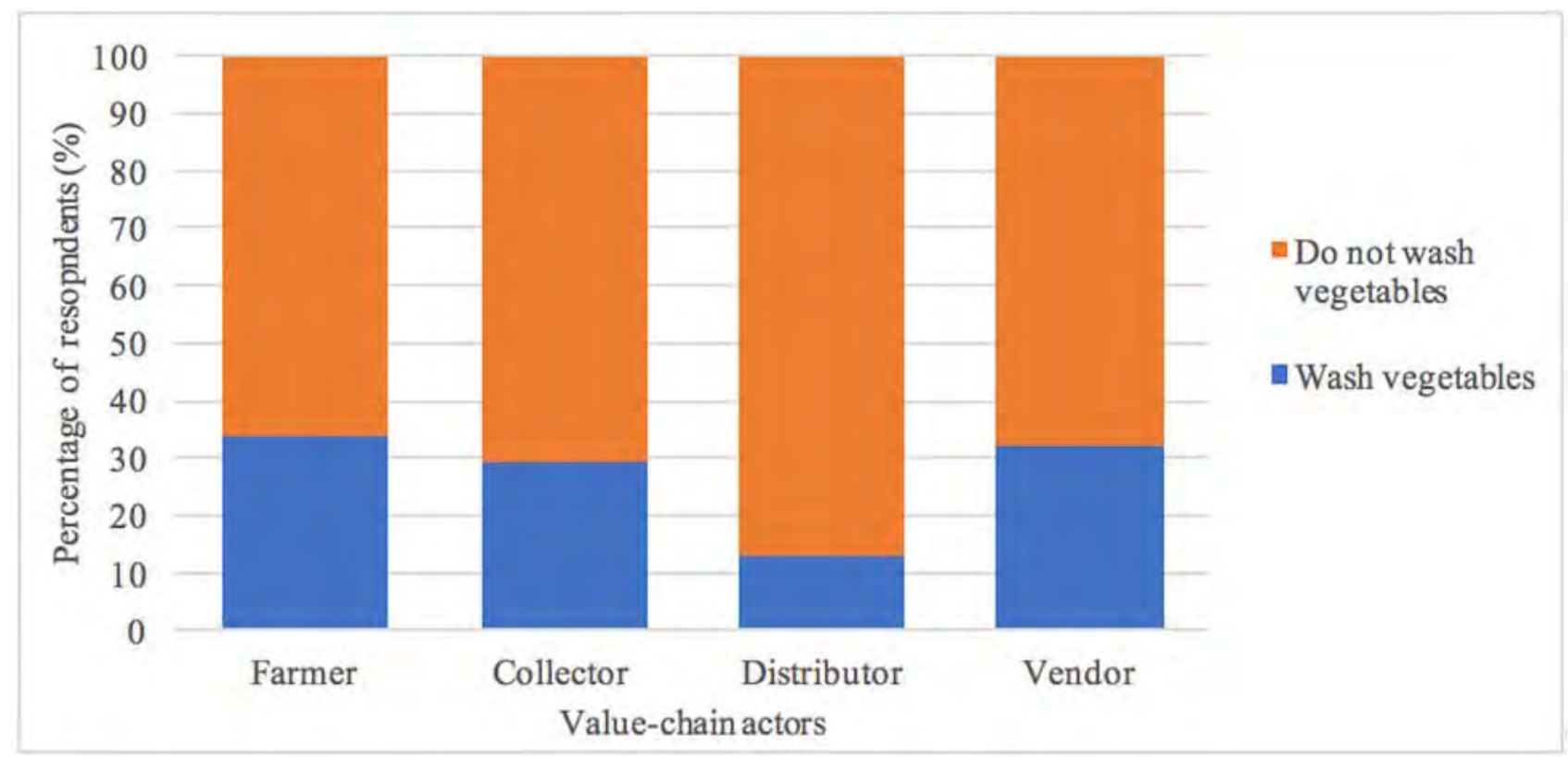

FIGURE 3. Vegetable washing practices by value-chain actor respondents ( $n=102$ farmers, $n=21$ collectors, $n=30$ distributors, $n=100$ vendors). 
animal waste that has undergone an aging process, although this "material" does not meet the usual standards of a true compost. Findings suggest that the median time interval between application of fresh manure and harvest was 3 days, with a minimum of 1 and a maximum of 365 days. The median aging time of "compost" was 13 days, with a minimum of 3 days and a maximum value of 120 days. Upon further conversation with the farmers, it was apparent that no specific composting procedure was routinely followed. The composting process, was not, however, observed or investigated in detail in this survey.

Responses about cleaning procedures revealed that more than half of the farmers $(66 \%)$ reported not cleaning harvested vegetables, for multiple reasons (Table 1, Fig. 3). Farmers who did indicate that they clean vegetables primarily washed them with ground water (98\%), while the remaining used surface water. Ground water in Cambodia has been shown to contain high levels of arsenic as well as generic Escherichia coli and coliforms $(7,21)$. In terms of storage, a high percentage (98\%) of farmers do not store harvested vegetable-crops on the farm for more than one day. In fact, a majority of the farmers (87\%) sell or transfer ownership of harvested vegetable crops multiple times a week (on harvest days) to different collectors, while the remaining farmers either sell the crops directly to a market vendor or sell the crops themselves at a market.

\section{Collectors}

Collectors are also defined as "middlemen" for farmers, distributors, and vendors in the vegetable value chain. It is important to note that fewer collectors than farmers exist in each province, because one collector will work with multiple farmers. The 21 collectors who participated in the study consisted of 13 males and 8 females; 11 were situated in BB and 10 in SR. Findings showed that $77 \%$ of collectors reported obtaining vegetables solely from farmers in Cambodia, 9\% solely from export markets (e.g., Thailand and Vietnam), and 14\% from both. A high percentage of collectors responded that they maintained a close business relationship with local farmers, as most of them (89\%) purchased from the same farmers every time.

Responses to cleaning procedure questions showed that $71 \%$ of the collectors do not wash received vegetables (Table 1, Fig. 3). The collectors who do wash vegetables do so by using either ground water $(50 \%)$ or surface water $(50 \%)$. After washing vegetables, a high percentage of collectors reported inspecting them for bruises or cuts (95\%) and handling bruised vegetables in several manners (Table 1, Fig. 4): cutting bruised vegetables, discarding bruised vegetables, and returning bruised vegetables to the sellers. Before transporting vegetables, $90 \%$ of collectors indicated, that they sort vegetables they have collected from different farmers by type and pack them in separate

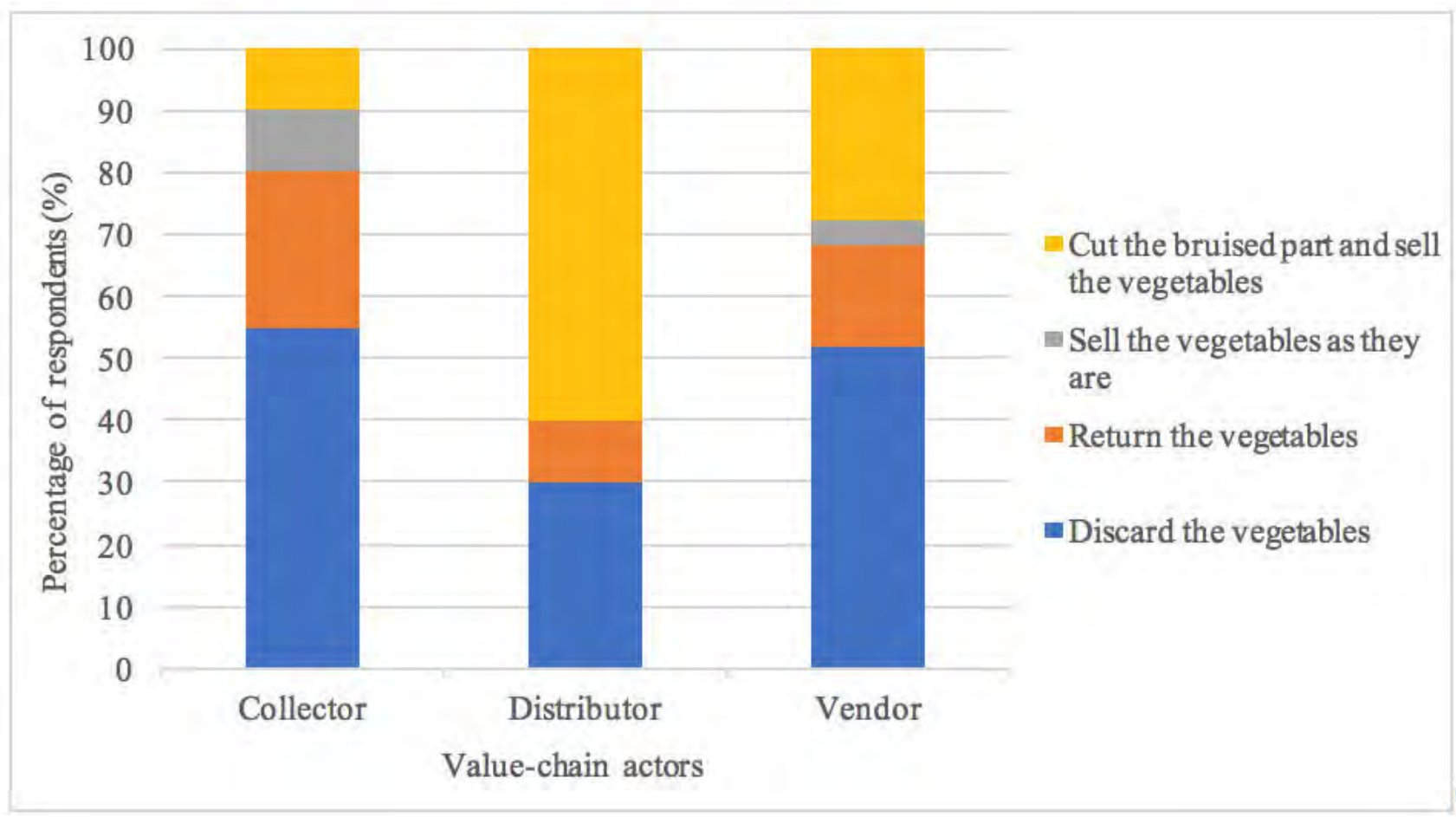

FIGURE 4. Bruised vegetables handling by value-chain actor respondents $(\mathrm{n}=102$ farmers, $\mathrm{n}=21$ collectors, $\mathrm{n}=30$ distributors, $\mathrm{n}=100$ vendors $)$. 
containers, which means that collectors mix vegetables from different sources. Large items (e.g., loose-leaf lettuce) are grouped and wrapped with fabric cloths, whereas smaller ones (e.g., tomatoes and cucumbers) are packed in plastic bundles. Approximately $81 \%$ of collectors reported not storing vegetables for more than one day. Vegetables are mostly delivered via cars and trucks to distribution centers (67\%) and informal markets (29\%) (Table 1). Findings regarding sanitation of transport vehicles revealed that only $67 \%$ of the collectors acknowledged that they cleaned their vehicles prior to transportation.

\section{Distributors}

Distributors are the wholesalers who sell horticulture crops in bulk quantity. This is the first point at which packed vegetables are displayed in a retail setting for purchase by potential buyers (e.g., individual vendors or other collectors). There are only a few distribution centers in each region of Cambodia, and each distribution center supplies multiple markets in that region. The 30 distributors in the study consisted of 21 females and 9 males. Distributors reported sourcing vegetables from several suppliers: collectors (50\%), export market (34\%) and local farmers (16\%) who deliver vegetables to the distribution centers. These findings show that distributors source vegetables from multiple value chain actors and that they are able to source from farmers or from export markets without the help of collectors. However, a close relationship between distributors and collectors was also observed, as most bought from the same collectors every time.

Questions on cleaning procedure revealed that $87 \%$ of distributors did not wash received vegetables, for several reasons (Table 1, Fig. 3). Distributors who clean vegetables reported using ground water $(67 \%)$, surface water (33\%) and municipal water (33\%). Approximately $97 \%$ of distributors reported inspecting crops for bruises. Bruised spots are most often cut out of vegetables by distributors before selling (Table 1, Fig. 4). In terms of packing of vegetable crops, large items (e.g., loose-leaf lettuce) are sold by individual weight to accommodate the needs of buyers (i.e., collectors, vendors); smaller crops (e.g., tomatoes and cucumbers) are sold in large bundles of a set weight.

Most distributors reported using multiple approaches for maintaining and cleaning stalls (Table 1). For example, most (57\%) of distributors reported replacing tarps used to display vegetables when the tarps show signs of damage. Additionally, $76 \%$ of distributors reported not using gloves while handling vegetables, while the remainder reported using reusable fabric gloves. Leftover vegetables are mostly stored at ambient temperature $(71 \%)$, in a container with ice $(24 \%)$ or in a refrigerator $(5 \%)$, to be sold the following day. Vegetables are sold from the distribution center to other collectors (70\%) and vendors (50\%).

\section{Vendors}

The vendors who participated in the study consisted of 100 females, of whom 46 are situated in BB and 54 are situated in SR. In the Cambodian vegetable value chain, most vendors are stationed in informal markets as individual vendors, and multiple informal markets exist within each province. A majority of vendors reported obtaining vegetables from collectors (71\%) rather than from distributors (23\%). Additionally, findings revealed that some informal market vendors are also farmers and are therefore selling their own harvested crops. Vegetables are primarily transported to the informal market by motorcycle (Table 1). Approximately $68 \%$ of vendors reported not washing vehicles before using them to transport vegetables; a high percentage of vendors (72\%) also reported not washing vegetables after receiving them (Table 1, Fig. 3). Of the vendors who reported washing vegetables, $46 \%$ stated that they use ground water, $33 \%$ stated that they use municipal water, and $21 \%$ stated that they use surface water to wash vegetables. Also, a high percentage of vendors reported inspecting received vegetables for bruises and cuts (74\%). Most bruised vegetables are discarded by vendors, but a fraction of bruised vegetables are cut or sold as they are (Table 1, Fig. 4).

Most vendors conduct cleaning activities in their stall before selling (Table 1), and more than half of the vendors $(67 \%)$ indicated that they replace tarps whenever damage occurred. Similar to distributors, $60 \%$ of vendors reported not using gloves, while the remainder reported using reusable fabric gloves. After selling, 95\% of vendors reported storing leftover crops in a container with ice $(79 \%)$, in a container at room temperature $(19 \%)$, or in a refrigerator $(1 \%)$, to be sold the following day.

A visual assessment was conducted in parallel with survey data collection for 52 vendors ( 15 in BB, 37 in SR) (Table 2, Fig. 5). Results of visual assessments were inconsistent with survey responses, as a majority of tarps being used in both markets were damaged. Moreover, a high percentage of vendors were observed using poor food safety practices. These included, but were not limited to, failure to remove their gloves and/or wash their hands after touching nonvegetable objects (e.g., money or the ground). Furthermore, observations of the stall vicinity revealed the presence of pests (e.g., rats, mice, insects), a lack of handwashing stations, or inadequate handwashing stations. Most (89\%) handwashing stations consisted of a bucket of water that was also being used to wash non-food items (the water was cloudy and contained visible organic matter). In addition, vegetables were being sold beside raw meat or raw fish. Handwashing stations were not widely available, and sanitation and hygiene within facilities was poor (i.e., not clean, had standing water, and had cracks on walls and floors) (Table 3). 


\section{TABLE 2. Detailed visual assessment observations on vendors ( $n=52$ vendors: $n=15 \mathrm{BB}$} and $n=37$ SR]

Visual assessment questions

Overall vendors (\%)
BB vendors

$(\%)$
SR vendors

What is the vendor set up?

(a) On the ground, with tarp

(b) Off the ground, with table and tarp

$37 \%$

$63 \%$

$20 \%$

\begin{tabular}{l|l}
$20 \%$ & $43 \%$ \\
\hline $80 \%$ & $57 \%$
\end{tabular}

Does the tarp show signs of damage (i.e., holes, frayed ends)?
(a) Yes
(b) No

$95 \%$

\begin{tabular}{|c|c|}
\hline $0 \%$ \\
\hline $100 \%$ \\
\hline
\end{tabular}

\begin{tabular}{|c|c}
$95 \%$ \\
\hline $5 \%$ \\
\hline
\end{tabular}

Does vendor wash hands after touching money or non-vegetable objects?
(a) Yes
(b) No

\begin{tabular}{|c|c|}
\hline $0 \%$ \\
\hline $100 \%$
\end{tabular}

\begin{tabular}{|c|c|}
\hline $0 \%$ \\
\hline $100 \%$ \\
\hline
\end{tabular}

\begin{tabular}{|c|c}
\hline $3 \%$ \\
\hline $97 \%$ \\
\hline
\end{tabular}

Are vendors using gloves?

\begin{tabular}{l|c|c|c} 
(a) Yes & $3 \%^{1}$ & $7 \%$ & $5 \%$ \\
\hline (b) No & $94 \%$ & $93 \%$ & $95 \%$ \\
\hline
\end{tabular}

Does vendor remove gloves after touching money or non-vegetable objects?

\begin{tabular}{l|c|c|c}
\hline (a) Yes & $0 \%$ & $0 \%$ & $0 \%$ \\
\hline (b) No & $100 \%$ & $100 \%$ & $100 \%$ \\
\hline
\end{tabular}

Are there signs of pests (e.g., rodents, insects) in the stall vicinity?

\begin{tabular}{l|c|c|c} 
(a) Yes & $96 \%$ & $100 \%$ & $95 \%$ \\
\hline (b) No & $4 \%$ & $0 \%$ & $5 \%$ \\
\hline
\end{tabular}

Are there handwashing stations near the stall?

\begin{tabular}{|l|c|c|c}
\hline (a) Yes & $52 \%$ & $7 \%$ & $70 \%$ \\
\hline (b) No & $48 \%$ & $93 \%$ & $30 \%$ \\
\hline
\end{tabular}

Are there stalls that sell raw meat or fish adjacent to the vegetables?

\begin{tabular}{l|l|l|l}
\hline (a) Yes & $52 \%$ & $53 \%$ & $51 \%$ \\
\hline (b) No & $48 \%$ & $47 \%$ & $49 \%$ \\
\hline
\end{tabular}

${ }^{1}$ All gloves observed were reusable gloves

\section{Province disaggregated results}

A higher percentage of female farmers were observed in SR (peri-urban,75\%), with fewer farmers in that province than in BB (rural) using inorganic fertilizers ( $45 \%)$. In contrast to farmers, a higher percentage of male collectors was observed in BB ( $82 \%)$ than in SR (40\%). Approximately $66 \%$ of farmers in both provinces reported not cleaning vegetables. A higher percentage of $\mathrm{BB}$ collectors (90\%) reported not washing received vegetables, in comparison to SR collectors (50\%).

Furthermore, vegetables are more often transported in cars and open cargo trucks in BB, whereas motorcycles are more often used in SR. However, a higher number of collectors in BB (54\%) than in SR (9\%) reported not cleaning vehicles before delivering vegetables. Findings about selling practices revealed that $96 \%$ of $\mathrm{BB}$ vendors and $82 \%$ of SR vendors reported cleaning their stalls before selling. A similar percentage of vendors reported changing floor tarps whenever they became damaged (62\% in BB, 58\% in SR), using fabric gloves (60\% in $\mathrm{BB}, 61 \%$ in $\mathrm{SR}$ ), and storing leftover vegetables at room temperature ( $96 \%$ in BB, $94 \%$ in SR). Visual assessment data were not disaggregated because of the unequal numbers of vendors observed in the two provinces.

\section{Gender disaggregated results}

Gender did not affect the distribution of vegetable crops cultivated, washing practices of vegetables, or choice of transportation vehicle to the distribution center. Females reported using more inorganic fertilizer $(0 \%$ males and 


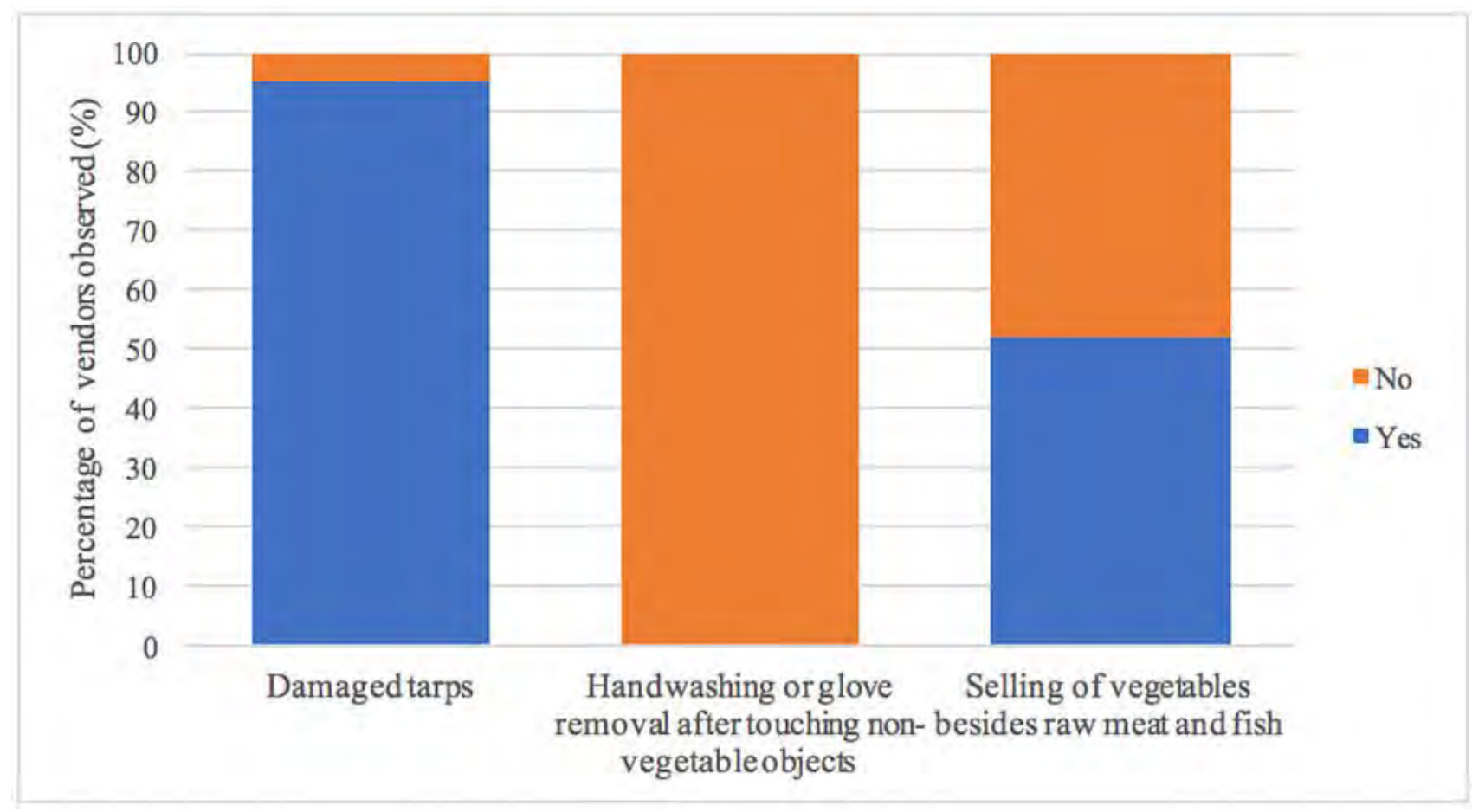

FIGURE 5. Visual assessments of vegetable handling and sanitary practices of vendors in Cambodian informal markets $(\mathbf{n}=52)$.

TABLE 3. Detailed visual assessment observations on markets' bathroom facilities ( $n=4$ bathrooms: $2 \mathrm{BB}$ and 2 SR)

Visual assessment questions

Is the restroom's interior clean upon first impression?

\begin{tabular}{|l|c|c|c}
\hline (a) Yes & $0 \%$ & $0 \%$ & $0 \%$ \\
\hline (b) No & $100 \%$ & $100 \%$ & $100 \%$ \\
\hline
\end{tabular}

Is there a handwashing station in the restroom?

\begin{tabular}{|l|c|c|c}
\hline (a) Yes & $25 \%$ & $0 \%$ & $50 \%$ \\
\hline (b) No & $75 \%$ & $100 \%$ & $50 \%$ \\
\hline
\end{tabular}

Are the walls and floors of the bathroom free of cracks?

\begin{tabular}{l|c|c|c}
\hline (a) Yes & $0 \%$ & $0 \%$ & $0 \%$ \\
\hline (b) No & $100 \%$ & $100 \%$ & $100 \%$ \\
\hline
\end{tabular}

Is the floor of the restroom dry and free of standing water?

\begin{tabular}{l|c|c|c}
\hline (a) Yes & $0 \%$ & $0 \%$ & $0 \%$ \\
\hline (b) No & $100 \%$ & $100 \%$ & $100 \%$ \\
\hline
\end{tabular}


$59 \%$ females) and were observed engaging in more cleaning practices of stalls when compared with males (56\% males and $95 \%$ females). Conversely, male farmers reported a preference for using organic fertilizers on vegetable plots, compared with female farmers (63\% and $39 \%$, respectively). Furthermore, male distributors, more often than female respondents ( $71 \%$ and $33 \%$, respectively), reported storing leftover vegetables at room temperature. Both male and female collectors reported using cars as their primary mode of transportation for delivering vegetables and similar percentages reported not cleaning vehicles before delivery (30\% of males and $37 \%$ of females). Overall, females represent a higher population of vegetable value chain actors than males, especially at the retail level (Fig. 6).

\section{DISCUSSION}

Overall, results suggest that the flow of vegetables in the value chain agrees with the results of Sokhen et al. (38). The flow of the value chain remains consistent, as findings from this study suggest a close relationship between actors in the value chain (e.g., distributors always purchase from the same collectors). Distribution of vegetables is also consistent with the existing literature, which reports that leafy greens and salad vegetables (e.g., lettuce, cucumbers) are grown in larger quantities than other types of vegetables on local farms (38).

Findings revealed that value chain actors practiced several behaviors that may contribute to cross-contamination at various stages of the value chain. These practices include the use of inadequately composted manure, improper intervals between manure application and harvest, infrequent washing practices, improper handling of cut vegetables, and unsanitary practices during transport and sale. In terms of soil amendments, findings from the study are inconsistent with results in the literature, which suggest that $80 \%$ of Cambodian farmers utilize fresh manure (11). Nonetheless, fresh manure as well as animal waste "compost" were used by farmers ( $33 \%$ and $11 \%$, respectively). Evidence from the scientific literature suggests the predominant use of swine manure in Cambodian farms (19). Improperly composted swine manure is a known source of foodborne pathogens, such as Salmonella enterica $(12,15,18)$. Responses to questions on composting methods were inconsistent, indicating that farmers may not be following specific guidelines on composting. Cambodia has adopted Codex Alimentarius texts for food safety, and these do not have specific recommendations on composting procedures; however, guidelines from foreign regulatory bodies (e.g., the United States Food \& Drug Administration) require that compost must meet specific criteria — for temperature, number of turns, and aging time and compositionwhich are not met by Cambodian farmers (43). For this reason, "compost" used by the Cambodian farmers does not meet international recommendations and may support the transfer of pathogens to vegetables $(6,29,36)$. Furthermore, responses on the interval between manure

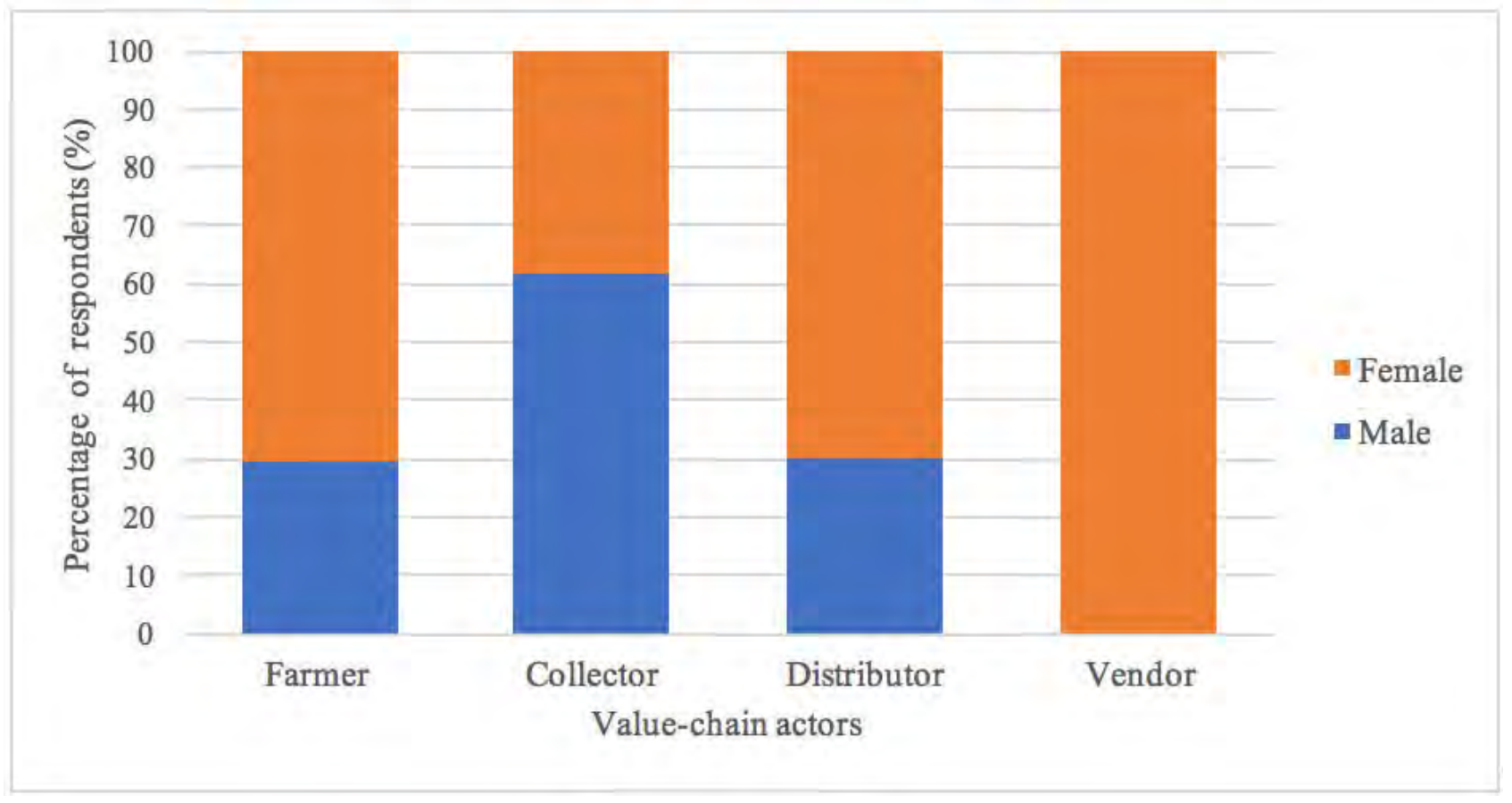

FIGURE 6. Gender demographic of value-chain respondents (102 farmers, 21 collectors, 30 distributors, 100 vendors). 
application and harvest were inconsistent with good food safety practices. Cambodia does not have recommendations for the harvest intervals after application of fresh manure on vegetable crops (e.g., USDA-National Organic Program rule indicates a minimum of 120 days between manure application and harvest for vegetables in contact with the soil and 90 days for all other crops); this lack of such a rule in Cambodia increases the likelihood of pathogens being present in the soil (42).

Proper washing is not frequently practiced by multiple actors across the vegetable value chain, in both provinces and by both males and females. Washing vegetables properly is a method of reducing parasitological and bacterial contamination $(1,14,20,29)$. However, it is critical to note that washing can negatively impact vegetable quality after storage and can increase post-harvest loss of vegetables, especially when washing is not followed by cool storage $(2,14)$. Cool storage is not a widespread practice among value chain actors in Cambodia, primarily due to lack of financial resources and assistance necessary for purchasing and operating refrigeration equipment. It is likely that value chain actors are choosing not to wash vegetable for this reason. More concerning, the practice of cutting bruised portions out of vegetables was commonly observed. This may exacerbate safety and quality concerns by increasing microbial proliferation and respiration of the cut produce $(9,14)$. The U.S. Centers for Disease Control and Prevention (CDC) and other United States institutions recommend always refrigerating produce that is cut beyond what is necessary in normal harvesting practices to ensure safety (8). For this reason, infrastructure development is needed to increase farmers' access to cool storage. Additionally, because of the absence of cool storage, washing in the value chain might not be an adoptable strategy to optimize food safety. Thus, at present, the responsibility for washing vegetables rests in the hands of consumers, and this should be effectively communicated, in the form of verbal communication by retailers, consumer training, consumer education and outreach programs, etc., to ensure that consumers understand that the vegetables being sold are not free from contaminants and that they share the responsibility for ensuring the safety of vegetables before consumption.

With regard to transport, vegetables are also not being delivered under cool temperatures, which further enhances microbial proliferation and spoilage $(9,14)$. The lack of sanitation of transport vehicles might introduce cross-contamination to the vegetables. Poorly sanitized transport vehicles, especially those that have been used to deliver animal products, can provide niches for pathogens and facilitate pathogen transmission to vegetables transported in the same vehicle $(5,33)$. Although this study did not explore whether animal products were also transported in the same vehicle, the possibility that the practice occurs must be considered.
Selling behaviors of vendors in distribution centers and informal markets might also introduce pathogens to vegetables, as well as support cross-contamination between vegetables. Improper sanitation practices of stalls increases the likelihood of survival of foodborne pathogens (e.g., Salmonella enterica) on non-food surfaces (39). Assessment results revealed inconsistency with survey findings (e.g., using damaged tarps), which is commonly observed in multiple consumer behavioral studies on food safety practices (32). The low frequency of handwashing and improper use of gloves (e.g., using fabric gloves, not removing gloves when touching non-food objects, not sanitizing before use) has been linked to multiple outbreaks caused by cross-contamination $(24,26)$. Crosscontamination of foodborne pathogens from raw meat and fish sources to vegetables has also been documented in multiple studies $(35,40)$. The likelihood of contamination is intensified by the low hygienic conditions in the bathroom facilities commonly used by vendors, which may support the spread of pathogen contamination across vendors in the market $(3,37)$.

Gender disaggregated findings revealed that male actors are more heavily engaged in on-farm and collection activities. Males, more often than females, were found to engage in on-farm practices that may contribute to contamination of vegetables (e.g., higher use of organic fertilizer, higher frequency of not properly cleaning stalls, higher frequency of storing vegetables at room temperature). This is consistent with past findings, primarily because women are predominantly responsible for household food preparation and purchases $(10,32)$. Furthermore, the greater involvement of women in the vegetable value chain, especially at retail, has been observed previously in Cambodia (16).

Several practices of value chain actors were identified as potential contamination points in the vegetable value chain. Intervention strategies such as targeted educational training programs, infrastructure development and regulatory control harmonization are encouraged. Training should focus on farmers to educate them on proper composting and manure application methods to prevent introduction of foodborne pathogens to vegetables. Training can also be targeted toward collectors, because of their personal relationship with farmers and their role as the bridge between production and the retail sector. Collectors can incentivize farmers to follow food safety practices by purchasing vegetables only from farmers who practice proper composting, etc. Vendors should also be trained on safe handling of vegetables, such as separation of meats from vegetables and proper handwashing in the market. Moreover, training should be oriented toward genderspecific findings. For example, females represent the predominant population of value chain actors, particularly vendors; thus targeting them will create a robust impact on 
the overall value chain and increase the effectiveness of the training. Additionally, training must be accompanied by financial assistance to develop infrastructure at distribution centers and markets to support food safety practices (e.g., cost to purchase and operate a refrigerator, clean water systems). Last, regulatory controls should be enacted to ensure that routine food safety practices are properly followed. Regulatory control includes setting guidelines to communicate the expectations of regulatory agencies for value chain actors and monitoring whether expectations are being followed. Coordination between regulatory and value-chain actors should be harmonized to ensure that good food safety practices are being communicated properly and effectively. The implementation of basic food hygiene practices at each step of the value chain will promote multi-hurdle food safety measures (e.g., cool storage, antimicrobial rinsing, and triple washing) and ultimately ensure the reduction or elimination of foodborne pathogens so as to prevent them from causing poor public health outcomes within the country. Future studies should focus on conducting a similar study in other provinces of Cambodia to create a more complete overview of the entire country, conducting consumer food safety behavior studies as well as collecting more vegetable samples for microbial analysis. The information will be a valuable resource for the development of suitable intervention strategies.

\section{ACKNOWLEDGMENTS}

This manuscript is made possible by the generous support of the American people through the United States Agency for International Development. The contents are the responsibility of the Horticulture Innovation Lab and do not necessarily reflect the views of USAID or the United States Government. We thank the faculty and students of Royal University of Agriculture-Phnom Penh, Cambodia, for their valuable insights and resources, which were essential to the completion of this project. We also thank the Horticulture Innovation Lab at University of CaliforniaDavis for financial support.

\section{REFERENCES}

1. Abougrain, A. K., M. H. Nahaisi, N. S. Madi, M. M. Saied, and K. S. Ghenghesh 2010. Parasitological contamination in salad vegetables in Tripoli-Libya. Food Control 21:760-762.

2. Bachmann, J., and R. Earles. 2000. Postharvest handling of fruits and vegetables, p. 1-19. In appropriate technology transfer for rural areas. Washington, D.C.

3. Barker, J., and S. Bloomfield. 2000. Survival of Salmonella in bathrooms and toilets in domestic homes following salmonellosis. J. Appl. Microbiol. 89:137-144.

4. Belfield, S. C., R. J. Martin, and J. F. Scott. 2013. Alternative cropping systems for northwest Cambodia. Int. J. Environ. Rural Dev. 4:209-214.

5. Beuchat, L. R. 1996. Pathogenic microorganisms associated with fresh produce. J. Food Prot. 59:204-216.

6. Beuchat, L. R., and J.-H. Ryu. 1997. Produce handling and processing practices. Emerg. Infect. Dis. 3:459-465.

7. Brown, J., S. Proum, and M. Sobsey. 2008. Escherichia coli in household drinking water and diarrheal disease risk: evidence from Cambodia. Water Sci. Technol. 58:757-763.

8. Centers for Disease Control and Prevention 2019. Fruit and Vegetable Safety. Available at: https://www.cdc.gov/foodsafety/ communication/steps-healthy-fruits-veggies. html. Accessed January 1, 2020.

9. Cortese, R. D. M., M. B. Veiros, C. Feldman, and S. B. Cavalli. 2016. Food safety and hygiene practices of vendors during the chain of street food production in Florianopolis, Brazil: A cross-sectional study. Food Control 62:178-186.
10. Dosman, D. M., W. L. Adamowicz, and S. E. Hrudey. 2001. Socioeconomic determinants of health- and food safety-related risk perceptions. Risk Anal. 21:307-318.

11. Eliste, P., and S. Zorya. 2015. Cambodian agriculture in transition: Opportunities and risks. World Bank: Washington, D.C.

12. Farzan, A., R. Friendship, A. Cook, and F. Pollari. 2010. Occurrence of Salmonella, Campylobacter, Yersinia enterocolitica, Escherichia coli $\mathrm{O} 157$ and Listeria monocytogenes in swine. Zoonoses and Publ. Health 57:388-396.

13. Food and Agriculture Organization of the United Nations. 2001. Urban and Peri-Urban Agriculture. Available at http://www.fao. org/unfaolbodies/coag/coag15/x0076e.htm. Accessed 30 January 2020.

14. Francis, G. A., C. Thomas, and D. O’Beirne. 1999. The microbiological safety of minimally processed vegetables. Int. J. Food Sci. Technol. 34:1-22.

15. Franz, E., and A. H. van Bruggen. 2008. Ecology of E. coli O157:H7 and Salmonella enterica in the primary vegetable production chain. Crit. Rev. Microbiol. 34:143-161.

16. Genova II, C., K. Weinberger, S. Sokhom, M. Vanndy, and E. C. Yarith. 2006. Postharvest loss in the supply chain for vegetables - the case of tomato, yardlong bean, cucumber and chinese kale in Cambodia. AVRDCWorldVegetableCenter, Shanhua, Taiwan.

17. Grace, D. 2015. Food safety in low and middle income countries. Int. J. Environ. Res. Publ. Health 12:10490-10507.

18. Grewal, S., S. Sreevatsan, and F. C. Michel, Jr. 2007. Persistence of Listeria and Salmonella during swine manure treatment. Compost Sci. Util. 15:53-62.
19. Huynh, T., A. Aarnink, A. Drucker, and M. Verstegen. 2006. Pig production in Cambodia, Laos, Philippines, and Vietnam: a review. Asian J. Agric. Rural Dev. 3:69-90.

20. Jung, Y., H. Jang, and K. R. Matthews. 2014. Effect of the food production chain from farm practices to vegetable processing on outbreak incidence. Microb. Biotechnol. 7:517-527.

21. Kang, Y. 2016. Arsenic-Polluted Groundwater in Cambodia: Advances in Research. Int. J. Water Wastewater Treat. 2:116-122.

22. KoBoToolbox. 2019. Simple, robust and powerful tools for data collection. Available at: https://www.kobotoolbox.org/. Accessed February 25, 2019.

23. Leistner, L. 1995. Principles and applications of hurdle technology, p. 1-21. In New methods of food preservation. Springer. Boston, MA.

24. Michaels, B., C. Keller, M. Blevins, G. Paoli, T. Ruthman, E. Todd, and C. J. Griffith. 2004. Prevention of food worker transmission of foodborne pathogens: risk assessment and evaluation of effective hygiene intervention strategies. Food Serv. Technol. 4:31-49.

25. Ministry of Agriculture Forestry and Fisheries. 2004. Country paper on food safety overview in Cambodia. Beijing, China.

26. Montville, R., Y. Chen, and D. W. Schaffner. 2001. Glove barriers to bacterial crosscontamination between hands to food. J. Food Prot. 64:845-849.

27. National Institute of Statistics Cambodia. 2019. General population census of the Kingdom of Cambodia. Ministry of Planning, Cambodia. 
28. National Institute of Statistics Cambodia, and Directorate General for Health. 2015. Cambodia demographic and health survey 2014. National Institute of Statistics, Ministry of Planning, Phnom Penh, Cambodia.

29. Natvig, E. E., S. C. Ingham, B. H. Ingham, L. R. Cooperband, and T. R. Roper. 2002. Salmonella enterica serovar Typhimurium and Escherichia coli contamination of root and leaf vegetables grown in soils with incorporated bovine manure. Appl. Environ. Microbiol. 68:2737-2744.

30. Olaimat, A. N., and R. A. Holley. 2012. Factors influencing the microbial safety of fresh produce: a review. Food Microbiol. 32:1-19.

31. Orriss, G. D., and A. J. Whitehead. 2000. Hazard analysis and critical control point (HACCP) as a part of an overall quality assurance system in international food trade. Food Control 11:345-351.

32. Patil, S. R., S. Cates, and R. Morales. 2005 Consumer food safety knowledge, practices, and demographic differences: findings from a meta-analysis. J. Food Prot. 68:1884-1894.
33. Ramesh, N., S. Joseph, L. Carr, L. Douglass, and F. Wheaton. 2002. Evaluation of chemical disinfectants for the elimination of Salmonella biofilms from poultry transport containers. Poult. Sci. 81:904-910.

34. Raspor, P. 2008. Total food chain safety: how good practices can contribute? Trends Food Sci. Technol. 19:405-412.

35. Roesel, K., and D. Grace. 2014. Food safety and informal markets. Taylor \& Francis, New York, NY.

36. Santamaría, J., and G. A. Toranzos. 2003. Enteric pathogens and soil: a short review. Int. Microbiol. 6:5-9.

37. Sinclair, R., and C. P. Gerba. 2011. Microbial contamination in kitchens and bathrooms of rural Cambodian village households. Lett. Appl. Microbiol. 52:144-149.

38. Sokhen, C., D. Kanika, and P. Moustier. 2004. Vegetable market flows and chains in Phnom Penh. French Ministry of Foreign Affairs, Hanoi, Vietnam.

39. Soumet, C., G. Ermel, V. Rose, N. Rose, P. Drouin, G. Salvat, and P. Colin. 1999. Identification by a multiplex PCR-based assay of Salmonella Typhimurium and Salmonella Enteritidis strains from environmental swabs of poultry houses. Lett. Appl. Microbiol. 29:1-6.

40. Tauxe, R. V. 2002. Emerging foodborne pathogens. Int. J. Food Microbiol. 78:31-41.

41. United Nations Children's Fund. 2018 Diarrhoea as a cause of death. Available at https://data.unicef.org/topic/child-health/ diarrheal-disease/. Accessed 29 July 2020.

42. U.S. Department of Agriculture. 2012. Guide for Organic Crop Producers. Washington, D.C.

43. U.S. Food and Drug Administration. 2019. CFR - Code of Federal Regulations Title 21 PART 112 - Standards for the growing, harvesting, packing and holding of produce for human consumption. Available at https:// www.accessdata.fda.gov/scripts/cdrh/ cfdocs/cfCFR/CFRSearch.cfm?fr=112.54. Accessed 29 July 2020. 